\title{
Effects of Waste Steel Fibers on Strength and Stress-strain Behavior of Concrete Incorporating Silica Nanopowder
}

\author{
Mohammad Haji Sotoudeh $^{1 *}$ and Mostafa Jalal ${ }^{2}$ \\ 'Power and Water University of Technology (PWUT), Tehran, Iran; haji2@pwut.ac.ir \\ ${ }^{2}$ Young Researchers Club and Elites, Science and Research Branch, Islamic Azad University, Tehran, Iran; \\ mjalal@pwut.ac.ir
}

\begin{abstract}
In the present experimental work, strength and stress-strain behavior of steel fiber reinforced concrete (SFRC) containing silica nanopowder has been investigated. The fibers used were waste steel slivers recovered from industrial wastes. First some tests were carried out in order to determine the characteristics of the Waste Steel Fibers (WSF). Different weight ratios of WSF as $0,1,3$ and $5 \mathrm{wt} \%$ were introduced into the concrete mix and the behavior of FRC samples were investigated under compression. A fraction of the cement as $3 \mathrm{wt} \%$ was also replaced by silica nanopowder. The results showed that introducing the WSF up to $5 \mathrm{wt} \%$ could improve the strength and ductility of the concrete. Besides, more uniform distribution of cracks was observed. Addition of nanopowders as $3 \mathrm{wt} \%$ also resulted in enhanced strength of the concrete which could be due to more packed and refined microstructure of the concrete and also more integrity of the fibers with the concrete mix. Silica nanoparticles as a partial replacement of cement could accelerate C-S-H gel formation as a result of increased crystalline $\mathrm{Ca}(\mathrm{OH})_{2}$ amount at the early age of hydration and hence increase the strength of concrete specimens.
\end{abstract}

Keywords: Concrete, Waste Steel Fiber, Silica Nanopowder, Strength, Stress-starin Behavior, Microstructure.

\section{Introduction}

Steel Fiber-Reinforced Concrete (SFRC) is currently used in a wide range of applications, including bridge decks, airport pavements, tunnels and others. SFRC is concrete made primarily from hydraulic cements, aggregates and discrete steel-reinforcing fibers. A variety of tests have been performed to determine the actual characteristics and advantages of fibrous materials. SFRC has advantages over traditionally reinforced concrete in civil engineering. Steel fibers are added to the concrete mix and they become an integral part of the wet concrete [1-6]. The addition of steel fibers aids in converting the brittle characteristics to ductile ones. The principal role of fibers is resisting the formation and growth of cracks by providing pinching forces at crack tips. In addition, a marginal improvement in tensile strength also results, and SFRC has higher ultimate strain than plain concrete [7-9]. SFRC always possesses a steeper descending stress-strain curve in compression, than does the normal-strength concrete. The rapid decrease in compressive strength in the post-peak load region brings about a pronouncedly brittle mode of failure. To foster the compressive strength without sacrificing the ductility, a strategy adopted is to add discrete steel fibers as reinforcement in concrete [10,11].

Many studies $[1,7,12,13]$ have been conducted to investigate the stress-strain behavior of SFRC. Teng et al. [1] adopted the equivalent inclusion method for studying the characteristics of the equivalent material properties of SFRC as a function of the volume fraction and the

${ }^{*}$ Corresponding author:

Mohammad Haji Sotoudeh (haji2@pwut.ac.ir) 
length-to-diameter ratio of the fibers. It is found that the equivalent materials moduli of concrete reinforce with randomly oriented and distributed fibers and they are insensitive to the length-to-diameter ratio of the steel fibers.

In the present study, the behavior of concrete reinforced by Waste Steel Fibers (WSF) has been assessed under compression. The fibers were introduced into concrete paste by different weight percentages (wt\%) and their effectiveness in strength and toughness of the concrete were evaluated. In order to improve the microstructure of the concrete binder, a fraction of Portlan Cement was replaced by silica nanopowder (3wt\%) so that the effect of nanopowder addition on strength and stress-strain behavior of SFRC samples could be investigated.

\section{Materials}

The materials used in this study could be divided into three parts, emphasizing their significance and influence on the aim of this study. First the concrete made up of aggregates, Portland Cement (PC) type $\Pi$ and tap water. The proportions of aggregates were designed based on recommendations of ACI211-1. Second, WSF which were provided from industrial wastes recovered from milling and machining process. The last part was silica nanopowder which was added to the concrete binder by $3 \mathrm{wt} \%$. The properties of silica nanopowder are as follows: diameter of $20 \pm 5 \mathrm{~nm}$, surface volume ratio of $165 \pm 17 \mathrm{~m}^{2} / \mathrm{g}$, density of $0.15 \mathrm{~g} / \mathrm{cm}^{3}$, and purity 99.9\%. Since waste steel fibers used in this study are considered to be of great importance taking into account the waste management aspect of the study, more details on preparation of fibers are presented in the following.

\subsection{Waste Steel Fibers Recovered from Industrial Wastes}

Since the studies of some earlier researchers who have worked on industrial waste fibers did not provide enough details on fibers characteristics and conditions, as a detailed study on fibers seemed inevitable. Whit this respect, to put more focus on waste steel fibers, direct investigation of industrial plants where waste steel slivers were produced from milling and machining operations was performed.
A part of waste fibers mostly resulted from warm milling and mild steel had desirable flexibility and tensile strength. But the waste fibers recovered from brittle steel milling and machining were cracked and did not have functionality to be used in concrete. More details on waste fibers and the process of fiber selection can be found from [9].

In this research, the slivers were cut manually by means of manual cutting gadget. The fibers after being cut into suitable lengths are shown in Figure 1.

Some sample fibers were randomly selected and tested so that their mechanical characteristics can be determined. Table 1 presents different measured properties of the fibers and average value and standard deviation of the results.

\section{Preparation of the Samples}

Initially the aggregates were added into the mixer and then the water and cement were added. Once the fresh concrete was prepared, the amount of concrete needed for plain specimens was taken from the mixture. In the next step, the prepared and scaled fibers based on the mixture design were added into the mixture.

Different volumes of fibers were added in several steps and before making the specimens of different percentage of fibers, slump was measured [9].

The molds were $30 \mathrm{~cm}$ in height are $15 \mathrm{~cm}$ in diameter. After casting, the molds were vibrated so that proper compaction of concrete was achieved. The samples were demoded after $24 \mathrm{~h}$ and the specimens were kept in the water basin until they reached the age of 28 days [9].

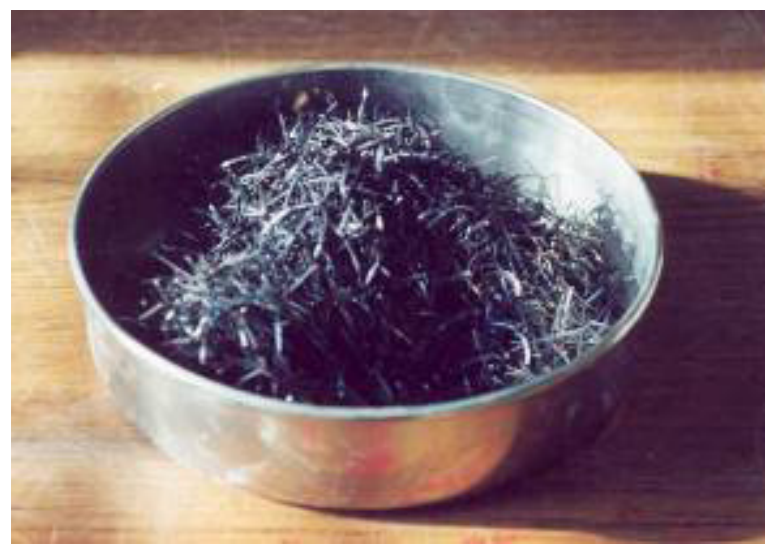

Figure 1. Recovered fibers after being cut into suitable lengths. 
Table 1. Mechanical characteristics of waste steel fibers (WSFs)

\begin{tabular}{|c|c|c|c|c|c|c|c|}
\hline No & $\begin{array}{l}\text { Length } \\
(\mathrm{mm})\end{array}$ & $\begin{array}{l}\text { Width } \\
\text { (mm) }\end{array}$ & $\begin{array}{c}\text { Thickness } \\
\text { (mm) }\end{array}$ & $\begin{array}{l}\text { Displacement } \\
(\mathrm{mm})\end{array}$ & $\begin{array}{l}\text { Strain } \\
(\mathrm{m} / \mathrm{m})\end{array}$ & $\begin{array}{l}\text { Force } \\
(\mathrm{N})\end{array}$ & $\begin{array}{l}\text { Strength } \\
\left(\mathrm{N} / \mathrm{mm}^{2}\right)\end{array}$ \\
\hline 1 & 21 & 2.5 & 0.6 & 1.2 & 0.05 & 1200 & 800.0 \\
\hline 2 & 21.3 & 1.7 & 0.5 & 2.31 & 0.10 & 800 & 941.2 \\
\hline 3 & 21.2 & 2.4 & 0.65 & 1.36 & 0.06 & 1200 & 769.2 \\
\hline 4 & 21.2 & 2.4 & 0.65 & 1.24 & 0.05 & 1200 & 769.2 \\
\hline 5 & 21.1 & 3 & 0.7 & 1.3 & 0.06 & 1200 & 571.4 \\
\hline 6 & 21.1 & 3 & 0.7 & 2.1 & 0.09 & 1200 & 571.4 \\
\hline 7 & 21.1 & 1.2 & 0.8 & 1.6 & 0.07 & 680 & 708.3 \\
\hline 8 & 22 & 1.55 & 0.55 & 1.5 & 0.06 & 800 & 938.4 \\
\hline 9 & 21.5 & 1.4 & 1.1 & 2.2 & 0.10 & 950 & 616.9 \\
\hline 10 & 21.5 & 1.55 & 0.8 & 0.9 & 0.04 & 800 & 645.2 \\
\hline 11 & 21.5 & 1.4 & 0.85 & 0.7 & 0.03 & 780 & 655.5 \\
\hline 12 & 21.5 & 2.45 & 0.65 & 1.05 & 0.04 & 1000 & 627.9 \\
\hline 13 & 21.5 & 2 & 0.75 & 1.1 & 0.05 & 1180 & 786.7 \\
\hline 14 & 22 & 1.25 & 1.1 & 1.5 & 0.06 & 950 & 690.9 \\
\hline 15 & 22 & 1.75 & 0.4 & 1.3 & 0.05 & 750 & 1071.4 \\
\hline 16 & 22 & 1.75 & 0.4 & 0.6 & 0.02 & 600 & 857.1 \\
\hline 17 & 21.5 & 2.6 & 0.45 & 1.1 & 0.05 & 980 & 837.6 \\
\hline 18 & 21 & 1.4 & 0.75 & 0.85 & 0.04 & 900 & 857.1 \\
\hline Ave & 21.44 & 1.96 & 0.68 & 1.32 & 0.06 & 953.88 & 761.97 \\
\hline $\mathrm{SD}$ & 0.35 & 0.59 & 0.20 & 0.48 & 0.02 & 203.32 & 139.23 \\
\hline
\end{tabular}

\section{Results, Discussion and Comparison}

\subsection{Stress-strain Behavior}

From the observation point of view in the plain concrete specimens, the failure was accompanied by separation of parts of the concrete. By increasing the fibers volume, after initiation of cracking, partial collapse and separation of the specimens decreased and in the specimens containing higher volume of fibers, uniformity of cracks and integration of the specimens were clearly noticed.

The characteristic of cracks continuity which was mainly due to fibers appeared more in higher volume of fibers. This characteristic not only improves the strength of concrete, but also causes better serviceability of the concrete. Fibers help better distribution of the cracks and it reduces crack and deformation concentration around weak parts and increases energy absorption of the concrete. It also appropriately prevents partial failure of the specimens. The data measured at the time of tests, i.e. length variations due to load application, were manipulated so that stresses and strains were obtained.

The steps and processes can be summarized as below:

- The weight of each specimen was determined before the test and the average density was calculated.

- Force and displacement readings at the time of test were recorded and after some processing were prepared for plotting the final stress-strain curve.

- The peak stress of the curve was determined as compressive strength of the specimen.

Presented in Table 2 are the test results obtained from the experiments.

As can be inferred from the table, the compressive strengths of FRC specimens containing 3 and $5 \mathrm{wt} \%$ of steel fibers are similar; being obvious that the compressive 
Table 2. Compressive strength results of FRC specimens

\begin{tabular}{lcccc}
\hline Code & $\begin{array}{c}\text { Nano } \\
\text { silica (\%) }\end{array}$ & Fiber (\%) & $\begin{array}{c}\text { Ave. density } \\
\left(\mathrm{g} / \mathrm{cm}^{3}\right)\end{array}$ & $\begin{array}{c}\text { Ave. } \\
\text { ultimate } \\
\text { strength } \\
(\mathrm{MPa})\end{array}$ \\
\hline FRC0 & 0 & 0 & 2.389 & 25.12 \\
FRC1 & 0 & 1 & 2.399 & 35.39 \\
FRC3 & 0 & 3 & 2.419 & 40.56 \\
FRC5 & 0 & 5 & 2.445 & 40.12 \\
FRC5-N3 & 3 & 5 & 2.440 & 45.22 \\
\hline
\end{tabular}

Source: Jalal M [9]

strength for $5 \mathrm{wt} \%$ addition of fibers is a little lower. However by incorporating $3 \mathrm{wt} \%$ of silica nanopowder in the binder of the concrete containing $5 \mathrm{wt} \%$ of fibers, about $12 \%$ enhancement of strength has been achieved. This may be due to the fact that nanoparticles can act as heterogeneous nuclei for cement pastes, further accelerating cement hydration because of their high reactivity, as nano-reinforcement, and as nano-filler, densifying the microstructure, thereby, leading to a reduced porosity. The most significant issue for all nanoparticles is that of effective dispersion.

The beneficial action of the nanoparticles on the microstructure and performance of cement-based materials can be explained by the following factors $[14,15]$ :

- nanoparticles fill the voids between cement grains, resulting in the immobilization of "free" water ("filler" effect);

- well-dispersed nanoparticles act as centers of crystallization of cement hydrates, hence accelerating the hydration;

- nanoparticles favor the formation of small-sized crystals (such as $\mathrm{Ca}(\mathrm{OH})_{2}$ and $\mathrm{AFm}$ ) and small-sized uniform clusters of $\mathrm{C}-\mathrm{S}-\mathrm{H}$;

- nanoparticles contribute in the pozzolanic reactions or accelerate them, resulting in the consumption of $\mathrm{Ca}(\mathrm{OH})_{2}$ and formation of an "additional" C-S-H gel;

- nanoparticles improve the structure of the aggregates' contact zone, resulting in a better bond between aggregates and cement paste;

- nanoparticles provide crack arrest and interlocking effects between the slip planes, which improve the toughness, shear, tensile and flexural strength of cement-based materials.
Stress- strain curves of the FRC samples are presented in Figure 2. The addition of fibers increased the stra in corresponding to the peak stress. The strain capacity and the elastic deformation capability of the concrete matrix in the pre-failure zone are increased considerably with the inclusion of steel fibers. Increase in peak strain, is higher for the samples having higher wt $\%$ of fibers and the highest for nano-containing sample. Both ascending and descending portion of the stress-strain curves are affected by the addition of steel fibers.

The area under the stress-straincurve is a measure of toughness of the material. Researchers have used different definitions for the toughness using the area under the curve. It is observed in the present work that the area under the stress-strain curve increases with the increase in fiber content.

For better illustration and comparison of the stressstrain curves of FRC samples, all of the curves are presented in one plane in Figure 3. Peak stresses can be easily compared for different FRC samples. The toughness as the area under the stress-strain curve is obviously turned out to be maximum for the sample containing 5 $\mathrm{wt} \%$ steel fibers and $3 \mathrm{wt} \%$ silica nanopowder.

\subsection{Microstructure of SFRC}

The microstructure of SFRC has been assessed through X-Ray Diffraction (XRD) spectra and Scanning Electron Microscopy (SEM). As Figure 4 shows, the peak related to formation of the hydrated products shifts to appear in earlier times indicating the positive impact of nanoparticles on formation of $\mathrm{Ca}(\mathrm{OH})_{2}$ and $\mathrm{C}-\mathrm{S}-\mathrm{H}$ gel at early age of cement hydration.

Concerning fibers integration with the concrete paste, as can be seen in Figure 5(a), the binding between fiber and the cement paste has been kept after failure of the specimen, however, in Figure 5(b) the fiber has been pulled out of the concrete and the residues of the cement paste can be observed on the fiber.

Figure 6 reveals the microstructure of the cement paste of the concrete at different ages investigated by SEM images. C-S-H gel which is existed in isolation is enclosed by some of needle-hydrates in the SEM of cement paste (Figure 6a). On the other hand, a more compact mixture after 28 days of curing has been achieved which indicates more formation of C-S-H gel (Figure 6b). The micrograph of the mixture containing nanopowder (Figure $6 \mathrm{c}$ ) reveals 

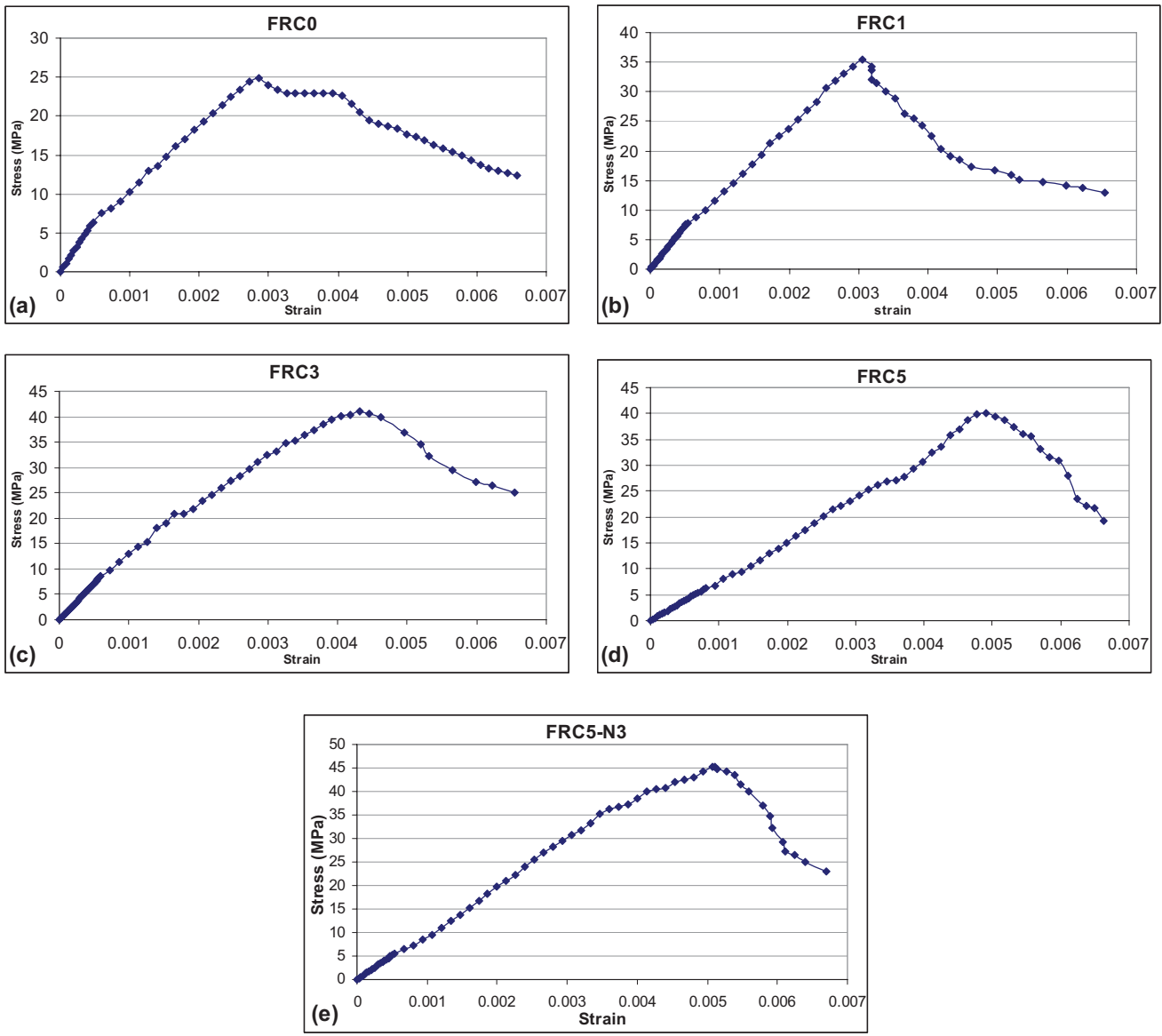

Figure 2. Stress-strain curves of the FRC samples containing (a) 0 wt \% fiber, (b) 1 wt $\%$ fiber, (c) 3 wt $\%$ fiber, (d) 5 wt $\%$ fiber, (e) 5 wt \% fiber and $3 \mathrm{wt} \%$ silica nanopowder.

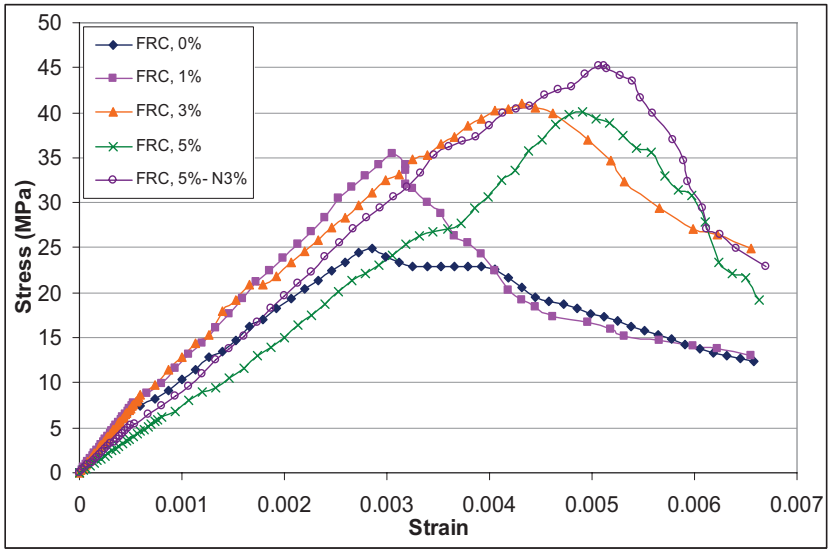

Figure 3. Comparison of the stress- strain curves for different FRC samples.

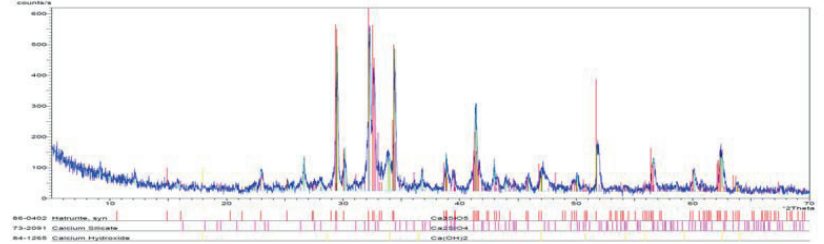

(a)

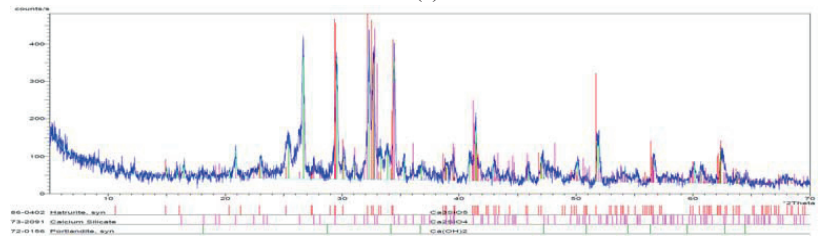

(b)

Figure 4. XRD spectra indicating the formation of hydrated products for specimens (a) without nanosilica and (b) with $3 \mathrm{wt} \%$ nanosilica. 


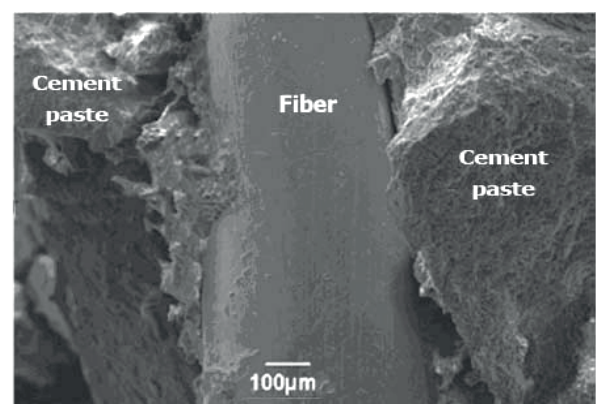

(a)

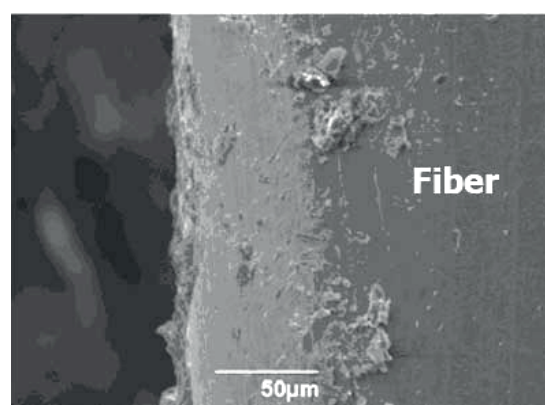

(b)

Figure 5. SEM micrographs of steel fiber reinforced concrete (SFRC): (a) steel fiber embedded in cement paste, (b) fiber pulled out from matrix.

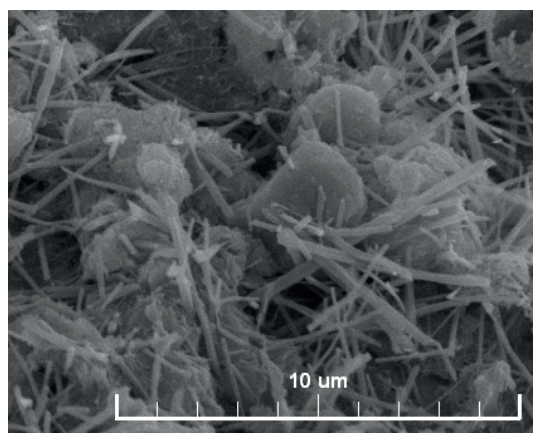

(a)

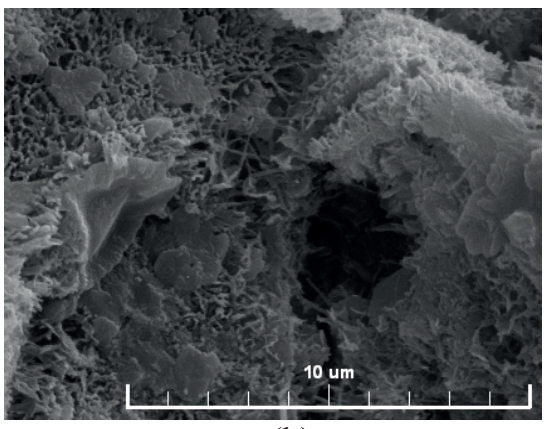

(b)

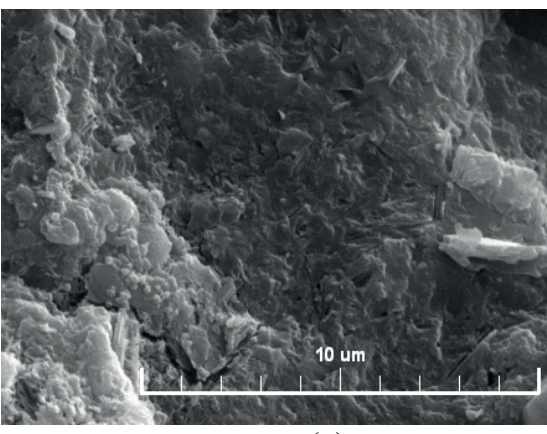

(c)

Figure 6. SEM micrograph of the cement pastes (a) after 7 days, (b) after 28 days without silica nanopowder, (c) after 28 days with $3 \mathrm{wt} \%$ silica nanopowder.

even more compact formation of hydration products and a reduced content of $\mathrm{Ca}(\mathrm{OH})_{2}$ crystals and more formation of $\mathrm{C}-\mathrm{S}-\mathrm{H}$ gel in presence of silica nanopowder.

The higher compressive strength in the mixture containing nanoparticles with respect to other specimens may be as a result of the rapid consumption of crystalline $\mathrm{Ca}(\mathrm{OH})_{2}$ which are quickly formed during hydration of Portland cement specially at the early ages as a result of high reactivity of silica nanoparticles. As a consequence, the hydration of cement is accelerated and larger volumes of reaction products are formed. Also silica nanoparticles recover the particle packing density of the blended cement, directing to a reduced volume of larger pores in the cement paste.

The mechanism that the nanoparticles improve the pore structure of concrete can be interpreted as follows [16]: suppose that nanoparticles are uniformly dispersed in concrete and each particle is contained in a cube pattern, therefore the distance between nanoparticles can be determined. After the hydration begins, hydrate products diffuse and envelop nanoparticles as kernel [17]. If the content of nanoparticles and the distance between them are appropriate, the crystallization will be controlled to be a suitable 
state through restricting the growth of $\mathrm{Ca}(\mathrm{OH})_{2}$ crystal by nanoparticles. Moreover, the nanoparticles located in cement paste as kernel can further promote cement hydration due to their high activity. This makes the cement matrix more homogeneous and compact, leading to more improved and refined pore structure of concrete.

On the whole, the addition of nanoparticles improves the pore structure of concrete. On the one hand, nanoparticles can act as a filler to enhance the density of concrete, which leads to the porosity of concrete reduced significantly. On the other hand, nanoparticles can not only act as an activator to accelerate cement hydration due to their high activity, but also act as a kernel in cement paste which makes the size of $\mathrm{Ca}(\mathrm{OH})_{2}$ crystal smaller and the tropism more stochastic.

\section{Conclusion}

The concluding remarks obtained from this experimental work can be summarized as:

- Addition of fibers increased the peak stress of the concrete samples under compression; however, for 3 and $5 \mathrm{wt} \%$ of fibers addition, the peak stresses were similar.

- Stress-strain behavior of the SFRC samples showed toughness improvement by fibers' increase, as the area under stress-strain curve increased which can be considered as energy absorption improvement of the concrete samples.

- Based on the stress-strain curve, addition of silica nanopowder to SFRC with $5 \mathrm{wt} \%$ of fibers enhanced the peak stress and also toughness of the concrete.

- Fibers' pull-out investigation by SEM images showed that by finer microstructure of the concrete binder (cement paste) achieved by nanopowder addition, the possibility of fibers' pull-out may be reduced.

- Microstructure assessment of the concrete by XRD and SEM showed that improved microstructure was achieved by incorporating silica nanopowder into the binder.

\section{References}

1. Teng T L, Chu Y A et al. (2004). Calculating the elastic moduli of steel-fiber reinforced concrete using a dedicated empirical formula, Computational Materials Science, vol 31(3-4), 337-346.
2. Ünal O (1994). Influence of heat treatment application on properties of fiber reinforced concrete, Doctoral thesis, I'stanbul Technic University, Civil Engineering Faculty (in Turkish).

3. İc-ağa $Y, \ddot{n}$ unal O et al. (2005). Investigation of physical and mechanical properties of fiber concretes cured in different conditions and exposed to freezing and thawing. Scientific Investigation Project, Afyon Kocatepe University, Project no: 042.TEF.02 (in Turkish).

4. ACI 544.1R-96 (1997). State-of-the-art report on fiber reinforced concrete, Chapter 2, American Concrete Institute (ACI) Committee, 544.1R-7-544.1R-24.

5. Craig J R (1984). Structural applications of FRC, Concrete International, 28-32.

6. Bayasi Z, Soroushian P (1992). Effect of steel fiber reinforcement on fresh mix properties of concrete, Technical Paper, ACI Materials Journal, vol 89(4), 369-374.

7. Ding Y, and Kusterle W (2000). Compressive stress-strain relationship of steel fibre-reinforced concrete at early age, Cement and Concrete Research, vol 30(10), 1573-1579.

8. Sorooshian P, and Bayasi Z (1991). Fiber type effects on the performance of steel fiber reinforced concrete, ACI Materials Journal, Technicl Paper, vol 88(2), 53-60.

9. Jalal M (2012). Compressive strength enhancement of concrete reinforced by waste steel fibers utilizing nano $\mathrm{SiO} 2$, Middle-East Journal of Scientific Research, vol 12(3), 382-391.

10. Song P S, and Hwang S (2004). Mechanical properties of high-strength steel fiber reinforced concrete, Construction and Building Materials, vol 18(9), 669-673.

11. Shah S P, and Rangan B V (1971). Fiber reinforced concrete properties, ACI Journal, 126-135.

12. Padmarajaiah S K, and Ramaswamy A (2002). A finite element assessment of flexural strength of prestressed concrete beams with fiber reinforcement, Cement \& Concrete Composites, vol 24(2), 229-241.

13. Nataraja M C, Dhang N et al. (1999). Stress-strain curves for steel fiber reinforced concrete under compression, Cement \& Concrete, Composites, vol 21(5-6), 383-390.

14. Sobolev K, and Ferrada-Gutiérrez M (2005). How nanotechnology can change the concrete world: part 1 , American Ceramic Society Bulletin, vol 84(10), 14-17.

15. Sobolev K, and Ferrada-Gutiérrez M (2005). How nanotechnology can change the concrete world: part 2, American Ceramic Society Bulletin, vol 11, 16-19.

16. Kondo R, and Yoshida K (1968). Miscibility of special elements in tricalcium silicate and alite and the hydration properties of C3S solid solutions, 5th International Symposium on the Chemistry of Cement, Tokyo, p.I-262.

17. Teoreanu I, Muntean M et al. (1987). Addition of titanium dioxide to Portland cement clinkers. Il Cemento, vol 84(4), 404-497. 